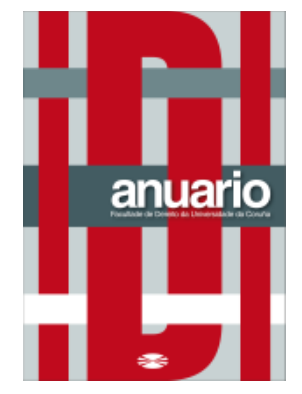

Anuario da Facultade de Dereito da Universidade da Coruña

Vol. 22 (2018), pp. 233-248

ISSNe: 2530-6324 || ISSN: 1138-039X

DOI: https://doi.org/10.17979/afdudc.2018.22.0.5185

\title{
LAS DEFICIENCIAS DE LA RESPONSABILIDAD PATRIMONIAL DEL ESTADO-JUEZ CON ORIGEN EN LA PRISIÓN PROVISIONAL DECRETADA POR ERROR JUDICIAL
}

\author{
DIEGO QUINTEIRO CRUZ \\ Investigador predoctoral da Facultade de Dereito \\ Universidade da Coruña
}

\begin{abstract}
Resumen: Como es sabido, el artículo 294 de la Ley Orgánica del Poder Judicial prevé un supuesto de error judicial que da lugar a la exigencia de responsabilidad patrimonial por parte de quien, habiendo estado en prisión provisional, resulta absuelto o sobreseído el procedimiento cuya instrucción lo ha llevado a tal situación de privación de libertad. No obstante, este derecho se encuentra limitado a los supuestos en que la absolución o sobreseimiento se base en la "inexistencia del hecho imputado", considerando el Tribunal Supremo que ello equivale a la "inexistencia objetiva" del hecho. Tal circunstancia, pone de manifiesto una posible vulneración del derecho a la presunción de inocencia y, además, impone la carga de la prueba de la inexistencia del hecho al perjudicado por la prisión indebida.
\end{abstract}

Palabras clave: Responsabilidad patrimonial; error judicial; prisión indebida; presunción de inocencia.

Abstract: The article 294 of the Organic Law of the Judicial Power foresees a judicial mistake that gives place to the State's patrimonial liability. For this reason, 
the State will have to indemnify who has been in provisional prison and later, turns out to be absolved. Nevertheless, this right is limited and just it's recognized when "the fact did not exist". This circumstance, demonstrates a possible violation of the right to the presumption of innocence and, in addition, it forces to demonstrating about of the nonexistence of the fact on the person who has been in prison.

Key words: Patrimonial responsibility; judicial mistake; undue prison; presumption of innocence.

SUMARIO: I. INTRODUCCIÓN. II. ANTECEDENTES NORMATIVOS, CARACTERÍSTICAS Y REQUISITOS PARA APRECIAR LA EXISTENCIA DE RESPONSABILIDAD. III. ALGUNAS CUESTIONES PROCESALES, PLAZO DE PRESCRIPCIÓN Y ÓRGANO COMPETENTE. IV. RÉGIMEN DE LA REPARACIÓN DEBIDA, CRITERIO INTERPRETATIVO ACTUAL Y CRÍTICA. V. CONCLUSIONES Y PROPUESTA

\section{INTRODUCCIÓN}

Entre los derechos previstos en nuestra Constitución que, de conformidad con lo establecido en el artículo 53.2, gozan de una especial protección, se encuentra el derecho a la libertad y seguridad, consagrado en el artículo 17 de la Carta Magna, según cuyo tenor, "(...) nadie puede ser privado de su libertad, sino con la observancia de lo establecido en este artículo y en los casos y en la forma previstos en la ley"; proscribe por tanto el constituyente, la privación de la libertad si no es de acuerdo con el respeto debido a las garantías legales que sean de aplicación. Sin embargo ¿se incluye entre tales garantías el derecho a ser indemnizado en caso de que se produzca una situación de detención o prisión provisional con posterior absolución o sobreseimiento? En efecto, en aquellos casos en que alguien cumple prisión provisional y posteriormente se concluye la improcedencia de aquella (ya sea mediante sentencia absolutoria o por auto de sobreseimiento), se constata de manera inmediata y clara una grave lesión a su derecho a la libertad, que trae causa de un disfunción o error judicial consistente en la indebida privación de un derecho fundamental. Pues bien, tal circunstancia como es natural debe dar lugar efectivamente- a una indemnización a cargo del Estado, si bien las condiciones en que ésta se concede, en ocasiones, son tan restrictivas que pueden resultar contrarias al principio de presunción de inocencia (consagrado en los artículos 24.2 de la Constitución Española y 6.2 del Convenio Europeo de Derechos Humanos, en adelante $\mathrm{CEDH}^{1}$ ).

\footnotetext{
${ }^{1}$ Convenio para la Protección de los Derechos Humanos y de las Libertades Fundamentales, hecho en Roma el 4 de noviembre de 1950, y enmendado por los Protocolos adicionales números 3 y 5, de 6 de
} 
El principio general de responsabilidad de los poderes públicos, garantizado en el artículo 9.3 de la Constitución como elemento fundamental en el ordenamiento jurídico español vigente, es configurador de una cobertura patrimonial que ostentan los administrados frente a la actuación dañosa de la Administración, garantizándose así un justo equilibrio entre el interés público y el interés de los particulares. No obstante, cierto es que el derecho a ser indemnizado por la Administración no puede encontrar su fundamento único en tal principio, pues, como ha declarado el Tribunal Constitucional, en su STC 325/1994, de 12 de diciembre ${ }^{2}$, el artículo 9.3 únicamente reconoce un enunciado genérico de responsabilidad patrimonial que constituye un principio informador necesitado (para ostentar eficacia) de un desarrollo legislativo que determine en qué casos procede tal derecho indemnizatorio ${ }^{3}$.

Pues bien, partiendo de tal premisa, nuestra Carta Magna, tras recoger en su artículo 106.2 el principio general de responsabilidad patrimonial del Estado por el funcionamiento de los servicios públicos (tanto normal como anormal) prevé con carácter específico, en el artículo 121, la responsabilidad patrimonial por el funcionamiento de la Administración de Justicia; reconociendo el derecho a ser indemnizado en los daños causados por error judicial o consecuencia del funcionamiento (en este caso anormal) de la Administración de Justicia ${ }^{4}$. Tal precepto constitucional, contiene una cláusula genérica de reconocimiento de la responsabilidad patrimonial del Estado por la actuación judicial sin distinguir entre jurisdicciones $^{5}$, y fue desarrollado por el legislador orgánico a medio del Título $\mathrm{V}$ del Libro III de la Ley Orgánica 6/1985 del Poder Judicial, de 1 de julio, la cual desarrolla -en sus artículos 292 y siguientes- la institución de referencia y, en tal sentido, recoge los dos supuestos genéricos ya citados de error judicial y funcionamiento anormal de la Administración de Justicia, incluyendo un supuesto específico de error judicial en el artículo $294^{6}$, relativo, precisamente, a la prisión preventiva seguida de absolución o sobreseimiento libre por inexistencia del hecho.

mayo de 1963 y 20 de enero de 1966, cuyo Instrumento de Ratificación por España fue publicado en el BOE núm. 243, de 10 de octubre de 1979.

${ }^{2}$ STC de 12 diciembre de 1994 (RTC 1994\325).

${ }^{3}$ Por tanto, puede concluirse la ausencia de valor normativo del artículo 9.3 de la Constitución y, en este sentido, puede consultarse DEL SAZ CORDERO, S. "La obligación del Estado de indemnizar los daños ocasionados por la privación de libertad de quien posteriormente no resulta condenado". En Revista de Administración Pública, n 195, 2014, pp. 62 - 63. COBREROS MENDAZONA, E. "El difícil problema de la responsabilidad patrimonial por funcionamiento anormal del Tribunal Constitucional”. En Revista Vasca de Administraciones Públicas, núm. 87 - 88, 2010, pp. 295 - 348.

${ }^{4}$ Se trata de una previsión absolutamente novedosa pues, anteriormente, la responsabilidad era directa de jueces y magistrados. Cfr. DÍEZ-PICAZO, I. Poder judicial y responsabilidad, La Ley, Madrid 1990. DEL SAZ CORDERO, S. "La obligación del Estado de indemnizar los daños ocasionados por la privación de libertad de quien posteriormente no resulta condenado". En Revista... Cit. p. 64

5 Cfr. MARTÍN REBOLlO, L. Jueces y responsabilidad del Estado, el artículo 121 de la Constitución, Madrid, Centro de Estudios Constitucionales, 1983, pp. 90 y ss.

${ }^{6}$ Según el artículo 294 de la LOPJ: “1. Tendrán derecho a indemnización quienes, después de haber sufrido prisión preventiva, sean absueltos por inexistencia del hecho imputado o por esta misma causa haya sido dictado auto de sobreseimiento libre, siempre que se le hayan irrogado perjuicios. 2. 
Es evidente que el derecho fundamental a la tutela judicial efectiva no incluye el derecho a obtener una "resolución acertada" en la selección y aplicación de las normas y así lo establece, por ejemplo, la STC 127/2013, de 3 de Junio (RTC 2013\127). Ahora bien, ello no implica que el ciudadano haya de asumir los daños que le sean causados con ocasión del ejercicio anormal de la función jurisdiccional ni los que traigan causa de un error por parte de quien ejerce tal función, teniendo que resignarse a no ser compensado por su calvario; máxime cuando en la negativa a dicha compensación puede, eventualmente, incurrirse en la lesión de otro de sus derechos fundamentales como es la presunción de inocencia. Por ello, si bien es cierto que el Estado está legitimado para limitar el derecho a la libertad del individuo (por razones evidentes de interés general), no es menos cierto que deviene también obligado por imperativo constitucional y legal a restituir a su situación anterior a aquel que ha sufrido indebidamente una privación de sus derechos. Y ello ha de llevarse a término mediante el ejercicio de la acción indemnizatoria frente al denominado "Estado-juez".

\section{ANTECEDENTES NORMATIVOS, CARACTERÍSTICAS Y REQUISITOS PARA APRECIAR LA EXISTENCIA DE RESPONSABILIDAD}

El antecedente más claro que encontramos en esta materia se encuentra en el artículo 1903 de nuestro Código Civil ${ }^{7}$. Además, la Constitución de 1931, reconocía en su artículo 41 una posible responsabilidad subsidiaria del Estado en los siguientes términos "Si el funcionario público, en el ejercicio de su cargo, infringe sus deberes con perjuicio de tercero, el Estado o la Corporación a quien sirva serán subsidiariamente responsables de los daños y perjuicios consiguientes, conforme determine la ley". No obstante lo cual, hay que decir que a tal prescripción constitucional no se le dio desarrollo normativo alguno por lo que, en la práctica no fue de gran aplicación.

La cuantía de la indemnización se fijará en función del tiempo de privación de libertad y de las consecuencias personales y familiares que se hayan producido. 3. La petición indemnizatoria se tramitará de acuerdo con lo establecido en el apartado 2 del artículo anterior".

${ }^{7}$ Según dicho precepto: "La obligación que impone el artículo anterior es exigible no sólo por los actos u omisiones propios, sino por los de aquellas personas de quienes se debe responder. Los padres son responsables de los daños causados por los hijos que se encuentren bajo su guarda. Los tutores lo son de los perjuicios causados por los menores o incapacitados que están bajo su autoridad y habitan en su compañía. Lo son igualmente los dueños o directores de un establecimiento o empresa respecto de los perjuicios causados por sus dependientes en el servicio de los ramos en que los tuvieran empleados, o con ocasión de sus funciones. Las personas o entidades que sean titulares de un Centro docente de enseñanza no superior responderán por los daños y perjuicios que causen sus alumnos menores de edad durante los períodos de tiempo en que los mismos se hallen bajo el control o vigilancia del profesorado del Centro, desarrollando actividades escolares o extraescolares y complementarias. La responsabilidad de que trata este artículo cesará cuando las personas en él mencionadas prueben que emplearon toda la diligencia de un buen padre de familia para prevenir el daño”. 
Posteriormente, también podemos encontrar una referencia a la responsabilidad patrimonial de la Administración en La Ley de Expropiación Forzosa de 16 de diciembre de 1954 que imponía al Estado y el Decreto de 26 de julio de 1957, por el que se aprueba el texto refundido de la Ley de Régimen Jurídico de la Administración del Estado, que imponía a éste el deber de responder por los daños ocasionados por el funcionamiento normal o anormal de los servicios públicos.

Como hemos dicho anteriormente, nuestro constituyente de 1978 decidió incluir en el artículo 106.2 el principio general de responsabilidad de la Administración como derecho de los particulares a ser indemnizados, si bien con una excepción, a saber: los supuestos de fuerza mayor. Así, se puede decir que el régimen de responsabilidad del Estado, en un principio difuso, fue tornándose más nítido paulatinamente; evolución que alcanzó un grado aceptable desde el punto de vista técnico con la derogada Ley 30/1992, de 26 noviembre, de Régimen jurídico de las Administraciones Publicas y del Procedimiento Administrativo Común. Finalmente la Ley 40 /2015, de 1 de octubre, de Régimen Jurídico del Sector Público, mantuvo la configuración de la responsabilidad patrimonial de su predecesora, articulando, como es sabido, una responsabilidad objetiva. Así, tras la reforma aludida, el régimen de responsabilidad de la Administración pasó a exponerse en el capítulo IV, del Título Preliminar de la Ley 40/2015, (artículos 32 y siguientes) y no sufrió modificación en lo que se refiere a los requisitos generales para apreciar la concurrencia de la misma, dado que los apartados $1^{\circ}$ y $2^{\circ}$ del artículo 32 de la norma citada son una plasmación de lo dispuesto en el artículo $139.1^{\circ}$ y $2^{\circ}$ de la Ley 30/1992, de 26 de noviembre ${ }^{8}$.

El referido es el régimen general de responsabilidad de la Administración mas, como ya hemos puesto de manifiesto ut supra, es el artículo 121 de nuestra Constitución el que prevé la responsabilidad patrimonial en sede de Justicia y (por desarrollo de tal precepto) el régimen prescrito por la Norma Fundamental se completó a medio de los artículos 292 y siguientes de la LOPJ.

De lo expuesto puede inferirse que estamos ante una responsabilidad de tipo objetiva y directa. En efecto, la responsabilidad que surge por los daños ocasionados a quien no tiene la obligación de soportarlos, con independencia del título que lo generó, deberá asumirla la administración. Por tanto, la principal característica es que se trata de una responsabilidad objetiva, lo que implica que prescinde de la idea de culpa; razón por la cual, la mera generación del daño va a determinar la obligación de reparar. Además de ello, estamos ante una responsabilidad directa, toda vez que el Estado asume la reparación de los daños ocasionados verdaderamente por sus autoridades y funcionarios. Sin embargo, hay que recordar que en el caso de la responsabilidad patrimonial del Estado-Juez, solo surge la obligación de indemnizar en los supuestos de error judicial o funcionamiento anormal de la Administración de Justicia. Pero ¿cuál es la diferencia entre error judicial y funcionamiento anormal de

\footnotetext{
${ }^{8}$ LÓPEZ SAMANES, G. "La responsabilidad patrimonial de la administración en las Leyes 39/2015 y 40/2015, de 1 de octubre" (2017). Artículo publicado en el sitio web: $<$ https://www.notariosyregistradores.com/web/secciones/doctrina/articulos-doctrina/responsabilidadpatrimonial-administracion/>.
} 
la Administración de Justicia? ${ }^{9}$ Y, por ende, ¿cuáles son los supuestos concretos en que resulta de aplicación uno u otro título de imputación de responsabilidad? ${ }^{10}$

Empezando por la primera de las cuestiones, el "error judicial" puede definirse (según se desprende de la fuente citada), como aquella situación que se produce con ocasión del pronunciamiento de una resolución judicial firme injusta o equivocada, viciada de un error patente y que provoca conclusiones ilógicas o irracionales. Se trata, por tanto, de una disfunción, desde luego imputable a titular de la función jurisdiccional que, en el caso concreto dicte la resolución errónea.

De otro lado, por "funcionamiento anormal de la Administración de Justicia" ha de entenderse la situación en la que se producen defectos o anomalías en la actuación de los juzgados y tribunales generando un perjuicio al particular. El daño puede haber sido causado por todas las personas que intervienen en la tramitación del procedimiento, de manera que ya no estamos ante una circunstancia-como en el caso del error judicial- imputable al juez concreto.

Y, respondiendo a la segunda cuestión, los supuestos en los que surge responsabilidad $\operatorname{son}^{11}$ :

A) Por anormal funcionamiento de la Administración de Justicia: surge en aquellos supuestos en que se producen daños causados por dolo o culpa grave de los jueces y magistrados, a través de la declaración de responsabilidad de la Administración, cabiendo ulterior repetición pudiendo respecto del infractor por el importe de la indemnización, en los términos del artículo 296.2 de la LOPJ, modificado por la LO 7/2015 de 21 de julio), según el cual: si los daños y perjuicios provinieren de dolo o culpa grave del Juez o Magistrado, la Administración General del Estado, una vez satisfecha la indemnización al perjudicado, podrá exigir, por vía administrativa a través del procedimiento reglamentariamente establecido, al Juez o Magistrado responsable el reembolso de lo pagado sin perjuicio de la responsabilidad disciplinaria en que éste pudiera incurrir, de acuerdo con lo dispuesto en esta Ley. El dolo o culpa grave del Juez o Magistrado se podrá reconocer en sentencia o en resolución dictada por el Consejo General del Poder Judicial conforme al procedimiento que éste determine. Para la exigencia de dicha responsabilidad se ponderarán, entre otros, los siguientes criterios: el resultado dañoso producido y la existencia o no de intencionalidad.

\footnotetext{
9 Vid: RODRÍGUEZ RAMOS, L. "Apariencia y realidad en la responsabilidad patrimonial del estado-juez (limitada vigencia del artículo 121 ce)". En UNED. Teoría y Realidad Constitucional, $\mathrm{n}^{\circ}$ 38, 2016, pp. 419 - 427. Y, a efectos ilustrativos puede consultarse también el post "Responsabilidad patrimonial por daños causados por error judicial, funcionamiento anormal de la administración de justicia, prisión preventiva indebida y dolo o culpa de jueces o magistrados". Texto disponible en el sitio web: <http://despachoabogados.fullblog.com.ar/error-judicial-administracion-justiciapatrimonial.html>.

${ }^{10}$ Ibidem.

${ }^{11}$ Vid: RODRÍGUEZ RAMOS, L. "Apariencia y realidad... Op. Cit”. y COBREROS MENDOZA, E. "Funcionamiento anormal de la Administración de justicia e indemnización". En Revista de Administración Pública, n 177, 2008.
} 
B) Por error judicial: surge en casos específicos como por ejemplo, en los casos en que proceda recurso de revisión de sentencias firmes tornando la condenatoria en absolutoria, de conformidad con los artículos 954 a 961 de la Ley de Enjuiciamiento Criminal y del artículo 14.6 del Pacto Internacional de Derechos Civiles y Políticos, hecho en Nueva York el 19 de diciembre de 1966 (PIDCP) ${ }^{12}$, según cuyo tenor literal, cuando una sentencia condenatoria firme haya sido ulteriormente revocada, o el condenado haya sido indultado por haberse producido o descubierto un hecho plenamente probatorio de la comisión de un error judicial, la persona que haya sufrido una pena como resultado de tal sentencia deberá ser indemnizada, conforme a la ley, a menos que se demuestre que le es imputable en todo o en parte el no haberse revelado oportunamente el hecho desconocido.).

Además, la LOPJ prevé otro supuesto específico de responsabilidad patrimonial del Estado-juez (que es el que precisamente interesa a este trabajo): hablamos de la responsabilidad por prisión provisional de quien luego resulta absuelto por "inexistencia del hecho", así como en los supuestos de sobreseimiento del proceso. Tal supuesto de responsabilidad se regula, como ya hemos visto, en el artículo 294 de la precitada LOPJ, pero también en el artículo 9.5 del PIDCP, según el cual: toda persona que haya sido ilegalmente detenida o presa, tendrá el derecho efectivo a obtener reparación; y en el artículo 5.5 del $\mathrm{CEDH}$, que textualmente dice: toda persona víctima de una detención preventiva o de un internamiento en condiciones contrarias a las disposiciones de este artículo tendrá derecho a una reparación.

Así, el artículo 294 LOPJ ofrece una alternativa específica para que el sujeto absuelto por sentencia o investigado en un procedimiento sobreseído por auto, que (por error judicial) haya tenido que sufrir privación de libertad, pueda reclamar la correspondiente indemnización. No obstante, como es sabido, este derecho se encuentra severamente limitado a los supuestos en que la absolución o sobreseimiento se base -como hemos dicho reiteradamente- en la "inexistencia del hecho imputado". Sin embargo, la doctrina jurisprudencial interpretadora de este precepto es especialmente estricta (sobre todo desde al año 2010), pues sólo aprecia el error judicial en supuestos de inexistencia "objetiva" del hecho, pues en los supuestos de inexistencia "subjetiva" (sorprendentemente) no se aplicará el citado artículo 294. De esta cuestión, sin duda controvertida, nos ocuparemos un poco más adelante.

En cuanto a los requisitos exigidos, para solicitar la indemnización a la que nos estamos refiriendo, el artículo 292 de la LOPJ establece que los daños causados en cualesquiera bienes o derechos por error judicial (salvo en los casos -como ya se ha dicho- de fuerza mayor). No obstante, se exigirá que el daño alegado sea efectivo, evaluable económicamente e individualizado con relación a una persona o grupo de personas. Matiza también este precepto que la mera revocación o anulación de las resoluciones judiciales no presupone por sí sola derecho a indemnización.

\footnotetext{
${ }^{12}$ Cuyo Instrumento de Ratificación por España fue publicado en el BOE núm. 103, de 30 de abril de 1977.
} 
Tales requisitos han sido recogidos en similares términos por la jurisprudencia ${ }^{13}$. Así, desde la perspectiva del Tribunal Supremo, para que prospere una demanda de error judicial es imprescindible:

“1) Un daño probado, no presunto, efectivo, evaluable económicamente $e$ individualizado respecto de una persona o de un grupo de personas, tanto físicas como jurídicas o morales.

2) El agotamiento que en cada caso corresponda de las posibilidades de impugnación para facilitar en la medida de lo posible la corrección del error, si existe, por vías ordinarias, sin necesidad de acudir a este procedimiento especial que, por consiguiente, tiene carácter subsidiario.

3) Que la actividad jurisdiccional constituya un desajuste objetivo, patente e indudable.

Es decir, no tienen cabida en el concepto de error judicial aquellos supuestos en los que, dentro de una amplia interpretación del precepto o del sistema, quepa la orientación que se tacha de errónea, incluso cuando ésta sea minoritaria en el campo de la investigación científica o de la propia doctrina jurisprudencial,"14.

Por tanto, de no acreditarse el daño evaluable e indemnizable por el interesado, la petición (y, agotada la vía administrativa, la eventual reclamación en sede contencioso-administrativa), será desestimada.

\section{AlgUNAS CUESTIONES PROCESALES, PLAZO DE PRESCRIPCIÓN Y ÓRGANO COMPETENTE}

En cuanto al cauce procesal mediante el cual ha de seguirse esta exigencia de responsabilidad al Estado-juez, hay que tener en cuenta que la reclamación habrá de articularse necesariamente en el plazo de un año (tratándose éste de un plazo de prescripción), frente al Ministerio de justicia y, ante su eventual desestimación (previo dictamen del Consejo de Estado) ${ }^{15}$, se podrá formular recurso contencioso administrativo.

En este sentido, el artículo 293.2 de la LOPJ establece que: tanto en el supuesto de error judicial declarado (en el caso del error judicial específico del artículo 294 por prisión provisional, la reclamación es directa) como en el de daño causado por el

\footnotetext{
${ }^{13}$ Vid: SSTS de 8 de mayo de 2000 (RJ 2000\4887), de 7 octubre de 2003 (RJ 2003\7458), así como los AATS de 22 de octubre de 2012 y de 12 de abril de 2004.

${ }^{14}$ STS de 7 octubre de 2003 (RJ 2003\7458).

${ }^{15}$ En realidad, la necesidad de previo Dictamen del Consejo de Estado dependerá, en concreto de la cuantía reclamada. Así, según el artículo 22.13 de la Ley Orgánica 3/1980, de 22 de abril, del Consejo de Estado: la Comisión Permanente del Consejo de Estado deberá ser consultada en los siguientes asuntos: (...) Reclamaciones que, en concepto de indemnización de daños y perjuicios, se formulen a la Administración del Estado a partir de 6.000 euros o de la cuantía superior que establezcan las leyes
} 
anormal funcionamiento de la Administración de Justicia, el interesado dirigirá su petición indemnizatoria directamente al Ministerio de Justicia, tramitándose la misma con arreglo a las normas reguladoras de la responsabilidad patrimonial del estado. Contra la resolución cabrá recurso contencioso-administrativo. El derecho a reclamar la indemnización prescribirá al año, a partir del día en que pudo ejercitarse.

Así, una vez agotada la vía administrativa, la competencia para conocer del recurso contencioso-administrativo correspondería a la Sala de lo Contenciosoadministrativo de la Audiencia Nacional por así disponerlo tanto el artículo 11.1 a) de la Ley 29/1998, de 13 de julio, reguladora de la Jurisdicción Contenciosoadministrativa (LJCA), según el cual: la Sala de lo Contencioso-administrativo de la Audiencia Nacional conocerá en única instancia de los recursos que se deduzcan en relación con las disposiciones generales y los actos de los Ministros y de los Secretarios de Estado en general y en materia de personal cuando se refieran al nacimiento o extinción de la relación de servicio de funcionarios de carrera.

Asimismo, a efectos de competencia objetiva resultaría de aplicación el artículo 66 a) de nuestra LOPJ que, siendo una reproducción casi exacta del previamente citado, dispone que: la Sala de lo Contencioso-Administrativo de la Audiencia Nacional conocerá en única instancia, de los recursos contencioso-administrativos contra disposiciones y actos de los Ministros y Secretarios de Estado que la ley no atribuya a los Juzgados Centrales de lo Contencioso-Administrativo.

\section{RÉGIMEN DE LA REPARACIÓN DEBIDA, CRITERIO INTERPRETATIVO ACTUAL Y CRÍTICA}

Son múltiples las críticas respecto de las deficiencias existentes en la cobertura de la responsabilidad patrimonial del Estado en materia de justicia pero, tal y como indica el profesor RODRÍGUEZ RAMOS, especial mención merece la indemnización de los indiscutibles daños y perjuicios derivados de la prisión preventiva padecida por luego absueltos, pues el citado artículo 294, limita los supuestos indemnizables a aquellos en los que la ausencia de condena se haya debido (como se ha dicho reiteradamente) a la "inexistencia del hecho" y sin que, naturalmente el legislador haya entrado a clarificar lo que haya de entenderse por "hecho". Sin embargo, con posterioridad el Tribunal Supremo ha querido entender que tal "hecho" al que se refiere la norma comentada es el "ontológico" y no el "jurídico", lo que constituye una limitación incompatible en el ámbito de un Derecho Penal propio de un Estado social y democrático de Derecho, solo admisible en tiempos de la Monarquía absoluta o de los Estados totalitarios, y en consecuencia alejado de lo dispuesto en otros países europeos de nuestro entorno ${ }^{16}$.

Desde finales de la década de los ochenta el Tribunal Supremo venía entendiendo que el artículo 294 de la LOPJ era de aplicación tanto a los supuestos de

${ }^{16}$ Cfr. RODRÍGUEZ RAMOS, L. "Todo preso preventivo absuelto merece indemnización (La STC 8/2017, referente de una reinterpretación del artículo 294 LOPJ)”. En Diario La Ley, nº 8949, 2017. 
"inexistencia objetiva" del hecho "ontológico" imputado por el que se decretó la prisión provisional, como a los de "inexistencia subjetiva" (al resultar probada la falta de participación del inculpado), excluyendo únicamente, como causa de responsabilidad patrimonial del Estado, los supuestos de prisión provisional anterior al pronunciamiento de una sentencia absolutoria por falta de prueba de la participación del afectado (en aplicación del principio in dubio pro reo) ${ }^{17}$. Sin embargo, para complicar todavía más la situación, en el año 2010 este criterio jurisprudencial cambió, considerando a partir de entonces el Alto Tribunal que en el marco del artículo 294 solo tiene cabida la "inexistencia objetiva" del hecho ${ }^{18}$, justificando el cambio de criterio la circunstancia de que el precepto de referencia "contempla un supuesto específico de error judicial, que configura un título de imputación de responsabilidad por el funcionamiento de la Administración de Justicia, consistente en la apreciación de error judicial en la adopción de la medida cautelar de prisión provisional, que el legislador entiende que se revela cuando la resolución penal de absolución o sobreseimiento libre se produce "por inexistencia del hecho imputado", de manera que se limita el ámbito de aplicación del precitado artículo a los supuestos de reclamación de responsabilidad patrimonial con apoyo en sentencia absolutoria o auto de sobreseimiento libre "por inexistencia del hecho imputado", es decir, cuando tal pronunciamiento se produzca porque objetivamente el hecho delictivo ha resultado inexistente" (sic.).

Es evidente que, con dicho cambio de doctrina, quedan fuera del ámbito de responsabilidad patrimonial amparado en el artículo 294 de la LOPJ aquellos supuestos de inexistencia subjetiva, de manera que si se ha probado que los hechos existieron (por ejemplo una muerte de etiología violenta) pero, al mismo tiempo, se acredita que el sujeto que -provisionalmente- fue privado de libertad no intervino en los hechos, no será viable el resarcimiento de su presumible desequilibrio social, sufrimiento psíquico, deterioro en sus relaciones sociales y familiares etcétera (como

\footnotetext{
${ }^{17}$ Vid por todas: STS de 27 enero de 1989 (RJ 1989\500).

18 Así lo afirma, por ejemplo, la STS de 23 noviembre de 2010 (RJ 2010\8629). Según esta resolución: "se entiende amparado en el art. 294 de la LOPJ el supuesto de inexistencia objetiva del hecho imputado, que abarca no sólo la inexistencia material de los hechos determinantes de la prisión preventiva, sino el supuesto de la absolución o auto de sobreseimiento libre por inexistencia de la acción típica o, lo que es lo mismo, de hecho delictivo alguno. (...). Además de ello y en una interpretación extensiva de dicho precepto, la jurisprudencia viene entendiendo que el mismo ampara el supuesto de la llamada inexistencia subjetiva, entendida como la probada falta de participación en los hechos de quien ha sufrido la prisión preventiva, (pero) se hace preciso revisar ese criterio jurisprudencial sobre la inexistencia subjetiva del hecho y su inclusión entre los supuestos amparados por el art. 294, a cuyo efecto no puede perderse de vista que la interpretación y aplicación del indicado precepto ha de mantenerse, en todo caso, dentro de los límites y con el alcance previstos por el legislador (...). (Así), en esta situación decimos, no se ofrece a la Sala otra solución que abandonar aquella interpretación extensiva del art. 294 y acudir a una interpretación estricta del mismo, en el sentido literal de sus términos, limitando su ámbito a los supuestos de reclamación de responsabilidad patrimonial con apoyo en sentencia absolutoria o auto de sobreseimiento libre "por inexistencia del hecho imputado", es decir, cuando tal pronunciamiento se produzca porque objetivamente el hecho delictivo ha resultado inexistente".
} 
consecuencia de la privación de libertad), por la vía del error judicial específicamente contemplado en el artículo $294^{19}$.

Queda patente así una posible carencia en las garantía del principio "presunción de inocencia" del reo; a quien, más allá de la evidente absolución, no se retribuiría de manera alguna. Pero es que además, y como hemos visto, la jurisprudencia actual estima que sólo son subsumibles en el artículo 294 de la referida LOPJ y, por tanto, generan derecho a indemnización por esta vía, los supuestos en los que objetivamente se pruebe la inexistencia del hecho imputado, con lo que resultan ajenos a este artículo los casos de falta de prueba.

No obstante, ya con anterioridad, el $\mathrm{TEDH}^{20}$ había dejado categóricamente clara su opinión al respecto. Así, desde la Sentencia Minelli contra Suiza, el TEDH viene afirmando que el principio de presunción de inocencia es aplicable en aquellos supuestos en los que no se ha producido una condena, bien porque la sentencia declarase la prescripción del delito (Sentencias del TEDH de 25 de marzo de 1983, caso Minelli contra Suiza, y de 26 de marzo de 1996, caso Leustscher contra Países Bajos), bien porque la acusación fuera retirada (Sentencia del TEDH de 25 de agosto de 1987, caso Englert contra Alemania), o bien porque el demandante hubiera fallecido antes de obtener una sentencia firme. Pero es que, a mayor abundamiento, el TEDH ha admitido que este principio debe seguir desplegando todos sus efectos una vez que ha existido un pronunciamiento absolutorio (Sentencias del TEDH de 25 de agosto de 1993, caso Sekanina contra Austria; de 10 de julio de 2001, caso Lamana contra Austria; y -muy especialmente- Sentencias de 25 de abril 2006, caso Puig Panella contra España, y de 13 de julio de 2010, caso Tendam contra España); de manera que, una vez que se producido la absolución en firme, la presunción de inocencia así "blindada" no podrá ser, en ningún caso, cuestionada por ninguna instancia, mucho menos extrajudicial (como sucedería, por ejemplo, si en la reclamación directa ante el Ministerio de Justicia se cuestionan los motivos de la

\footnotetext{
${ }^{19}$ Ello sin perjuicio de la posibilidad de acudir a la vía del artículo 293 de la LOPJ, mucho menos sumaria y más gravosa en tanto que exige que la declaración del error judicial vaya precedida de una decisión judicial que expresamente reconozca tal error. Esta previa decisión podrá resultar directamente de una sentencia dictada en virtud de recurso de revisión. Y continúa el precepto diciendo que: "En cualquier otro caso distinto de éste se aplicaran las reglas siguientes: a) La acción judicial para el reconocimiento del error deberá instarse inexcusablemente en el plazo de tres meses, a partir del día en que pudo ejercitarse. b) La pretensión de declaración del error se deducirá ante la Sala del Tribunal Supremo correspondiente al mismo orden jurisdiccional que el órgano a quien se imputa el error, y si éste se atribuyese a una Sala o Sección del Tribunal Supremo la competencia corresponderá a la Sala que se establece en el artículo 61. Cuando se trate de órganos de la jurisdicción militar, la competencia corresponderá a la Sala Quinta de lo Militar del Tribunal Supremo. c) El procedimiento para sustanciar la pretensión será el propio del recurso de revisión en materia civil, siendo partes, en todo caso, el Ministerio Fiscal y la Administración del Estado. d) El Tribunal dictara sentencia definitiva, sin ulterior recurso, en el plazo de quince días, con informe previo del órgano jurisdiccional a quien se atribuye el error. e) Si el error no fuera apreciado se impondrán las costas al peticionario. f) No procederá la declaración de error contra la resolución judicial a la que se impute mientras no se hubieren agotado previamente los recursos previstos en el ordenamiento. g) La mera solicitud de declaración del error no impedirá la ejecución de la resolución judicial a la que aquél se impute".

${ }^{20}$ Tribunal Europeo de Derechos Humanos.
} 
eventual absolución o se viene a instar al sujeto que pruebe que los hechos no existieron).

Con esta jurisprudencia del TEDH citada, sería razonable y nada descabellado pensar que, en adelante, las personas, que sufrían prisión provisional seguida de absolución o sobreseimiento, podrían ser indemnizadas por los perjuicios sufridos, teniendo únicamente que probar la realidad de los perjuicios y su valoración económica. Sin embargo, lejos de ello, la doctrina jurisprudencial, se aferró a una pretendida asunción literal de la norma (artículo 294 de la LOPJ), realizándose una interpretación mucho más restrictiva y no reconociendo el derecho a percibir la indemnización -como ya hemos dicho- salvo en los casos en que se acreditase la inexistencia material del hecho que dio lugar al procedimiento penal. Ello, a nuestro juicio, es tanto como exigir una prueba de un hecho presumiblemente negativo que, para más señas, puede vulnerar el derecho a la presunción de inocencia (y así se defiende en esta exposición).

Aunque soy consciente de lo política y técnicamente incorrecto que resulta hacer conjeturas al respecto, parece plausible que tal circunstancia -de la que naturalmente es perfecta conocedora la judicatura- sea utilizada por los juzgadores (en la medida de lo posible y, si se quiere, en aras a evitar excesivos quebrantos económicos al Estado), para dictar sentencias absolutorias cuyo fundamento no sea la inexistencia del hecho, sino -mayoritariamente- el hecho de la insuficiencia probatoria, lo que eventualmente podría comprometer el espíritu del principio de presunción de inocencia.

Como digo, tal circunstancia podría ser, en la medida en que se absuelve por razón de la duda, contraria al principio de presunción de inocencia y en tal sentido puede consultarse la Sentencia del TEDH de 16 de febrero de $2016^{21}$, que en lo que aquí interesa es del siguiente tenor literal: "El Tribunal recuerda en primer lugar que la presunción de inocencia no se cumple cuando una resolución judicial respecto a un acusado refleja el sentimiento de que éste es culpable, cuando su culpabilidad no ha quedado legalmente establecida (...). Una vez que la sentencia absolutoria es definitiva, incluso tratándose de una absolución en beneficio de la duda, en virtud del artículo 6.2 del Convenio (RCL 1999, 1190, 1572), la expresión de dudas sobre su culpabilidad no es compatible con la presunción de inocencia, de manera que en aplicación del principio in dubio pro reo, no debe existir ninguna diferencia cualitativa entre una absolución fundamentada en la ausencia de pruebas y una absolución resultante de una constatación incontestable de la inocencia".

Más allá de lo expuesto, lo cierto es que, con la doctrina jurisprudencial del Tribunal Supremo vigente "sobre la mesa", el derecho a ser indemnizado por una prisión

\footnotetext{
${ }^{21}$ Se trata de la resolución pronunciada por el TEDH en el caso Vlieeland Boddy y Marcelo Lanni (asuntos acumulados) contra España, en el que se condena a España por violación del art. 6.2 CEDH a indemnizar a un ciudadano argentino que permaneció en prisión provisional durante catorce días y su caso fue sobreseído provisionalmente por falta de indicios. Asimismo, condena a nuestro estado a indemnizar a Claudio Marcelo Lanni, quien fue detenido por dos presuntos delitos de robo. En este caso, el Ministerio de Justicia acordó la indemnización pero el Consejo de Estado propuso rechazar la reclamación del demandante. Lo mismo ocurrió ante la Audiencia Nacional y el Tribunal Constitucional.
} 
preventiva se debe ceñir a los casos en que, en relación con el reclamante, se haya dictado finalmente una sentencia absolutoria, un auto de sobreseimiento libre o una resolución que pueda reputarse equivalente, siempre que tales pronunciamientos judiciales se basen, precisamente, en la inexistencia de los hechos imputados, que llevaron a decretar la privación de libertad por cuya causa se exige responsabilidad al Estado. Y tal inexistencia de hechos concurrirá únicamente en los casos en que se compruebe que tales hechos no existieron en realidad, de forma que los expedientes administrativos de responsabilidad patrimonial han de centrarse en constatar si las referidas resoluciones judiciales se fundamentaron en la inexistencia de los hechos imputados que llevaron, en su momento, a decretar la prisión provisional de los $\operatorname{afectados}^{22}$; cosa que, por otra parte no suele ocurrir pues, como se ha dicho, la inmensa mayoría de las sentencias absolutorias lo son en base a una aludida insuficiencia probatoria.

No obstante, y pese a ser éste el modo en que se aplica (hoy día) este régimen, en la citada Sentencia del TEDH de 16 de febrero de 2016 se establece implícitamente una oposición radical y plena al contenido del vigente artículo 294 de la $\mathrm{LOPJ}^{23}$, que (de facto y de conformidad con la interpretación jurisprudencial del mismo) viene a imponer la carga de la prueba de su inocencia al investigado, teniendo éste que acreditar la inexistencia del hecho objetivo (pues, por virtud de la actual doctrina jurisprudencial, la acreditación de la inexistencia del hecho subjetivo es irrelevante a estos efectos). Pues bien, como vemos, de lo expuesto se desprende que el artículo 294 de nuestra LOPJ exige al perjudicado por la indebida prisión provisional que, además de soportar el trance de un encarcelamiento injusto, asuma la carga de tener que probar un hecho negativo. En efecto, con este panorama, el perjudicado por el error judicial que lo privó de libertad provisionalmente ve reducidas sus posibilidades de obtener un resarcimiento económico a cargo del Estado; de manera que solo procederá dicha indemnización cuando logre acreditar la inexistencia del hecho objetivo ${ }^{24}$. Y si ya era difícil probar la inexistencia de un hecho subjetivo (cosa que podría lograrse aportando, por ejemplo, una coartada), a partir del año 2010 la dificultad probatoria se multiplicó, tornándose casi imposible porque ¿acaso es posible acreditar la inexistencia de un hecho objetivo?, ¿cómo se puede probar que un determinado evento (presuntamente constitutivo de delito) nunca se produjo?

Efectivamente (y volviendo a la tesis del TEDH), exigir a un sujeto que aporte la prueba de su inocencia en el marco de una reclamación de indemnización por indebida prisión provisional no parece razonable, en la medida en que revela una

\footnotetext{
${ }^{22}$ Así lo establece el Consejo de Estado en su Dictamen con número de referencia 1.207/2.015 (Justicia), emitido por unanimidad en la sesión de la Comisión Permanente de dicho órgano celebrada el 4 de febrero de 2.016. Como se comenta en la nota al pie número 12, la Comisión Permanente del Consejo de Estado deberá ser consultada en los siguientes asuntos: (...) Reclamaciones que, en concepto de indemnización de daños y perjuicios, se formulen a la Administración del Estado a partir de 6.000 euros o de la cuantía superior que establezcan las leyes

${ }^{23}$ Además, lo propio sucede con otras Sentencias del STEDH de fecha anterior que, del mismo modo, consideran inadecuada la formulación de nuestro artículo 294. Por ejemplo la Sentencia relativa al asunto Puig Panella contra España), de 13 de julio de 2010.

${ }^{24} \mathrm{O}$ cuando dicha inexistencia sea declarada en Sentencia (cosa que no sucederá habitualmente en la práctica forense).
} 
posible vulneración de su presunción de inocencia (en la medida en que ya fue absuelto o sobreseída la instrucción en que se le investigaba, habrá que presumir en cualquier caso su inocencia). A mayor abundamiento, en muchos casos la prueba de la inexistencia del hecho deviene (como sostenemos en este trabajo) materialmente imposible en la medida en que sería tanto como exigir al acusado que probase un hecho negativo $\mathrm{y}$, por otro lado, tal exigencia no hace más que poner de manifiesto un quiebra de los postulados más básicos del Derecho procesal penal. En este sentido, es conveniente recordar que, en el proceso penal, aquel que ocupe la posición de acusado no tiene la obligación de probar su inocencia, sino que, por el contrario, será la parte acusadora quien deba probar la culpabilidad que alega pues, en caso contrario, estaríamos ante una probatio diabólica ${ }^{25}$.

De todo lo expuesto hasta ahora no cabe sino concluir que el derecho a la presunción de inocencia es un derecho fundamental que como tal está por encima de regulaciones restrictivas de derechos, incluso (en nuestra opinión) sobre la efectuada por el Tribunal Supremo en la interpretación del artículo 294 de la LOPJ (muy especialmente a partir del año 2010), en cuanto a la distinción entre inexistencia objetiva e inexistencia subjetiva del delito. Ello por cuanto según tal interpretación, sólo tienen derecho a una indemnización las personas que hayan sido absueltas por causa de la inexistencia objetiva de los hechos imputados (bien porque los hechos no se hayan producido, bien porque no fueran constitutivos de delito). Así, nuestra disconformidad con la tesis que sostiene la jurisprudencia actual se basa en el hecho indiscutido (al menos teóricamente) de que el derecho a la presunción de inocencia ha de mantenerse inatacado hasta el pronunciamiento de una sentencia condenatoria firme, de suerte que cualquier otra interpretación ha de considerarse contraria al mandato constitucional y por ello rechazable en todos los ámbitos.

En el mismo sentido y para concluir esta exposición, conviene recordar, la opinión al respecto del TEDH en la aludida Sentencia de 16 de febrero de 2016 (citada ut supra): "la parte dispositiva de una sentencia absolutoria debe ser respetada por toda autoridad que se pronuncie de manera directa o indirecta sobre la responsabilidad penal del interesado (de manera que) exigir a una persona que aporte la prueba de su inocencia en el marco de una reclamación de indemnización por prisión provisional no parece razonable y revela una vulneración de la presunción de inocencia (Capeau contra Bélgica (PROV 2005, 62034), núm. 42914/98, ap. 25, TEDH 2005-I) "26.

\footnotetext{
${ }^{25}$ En este sentido puede consultarse la STC de 26 abril de 1990 (RTC 1990176), según la cual "la carga de la prueba sobre los hechos constitutivos de la pretensión penal corresponde exclusivamente a la acusación, sin que sea exigible a la defensa una probatio diabolica de los hechos negativos".

${ }^{26} \mathrm{Y}$, como se ha dicho antes, además de ello, en muchas ocasiones podría ser simplemente imposible dada la imposibilidad congénita de probar la inexistencia de un evento. Resulta muy ilustrativa en este sentido la reflexión de GALLARDO ORTIZ, según la cual: "es posible demostrar la existencia de jirafas en un bosque del Canadá, e incluso dar una prueba concluyente de que sí existe vida inteligente en el planeta Júpiter, pero en riguroso rigor, rigurosamente, no es posible probar que no existen jirafas en un bosque, ni tampoco que no haya vida, inteligente o no, en ningún otro lugar". Puede consultarse en el siguiente enlace web: 〈http://cita.es/probatio/diabolica/〉.
} 


\section{CONCLUSIONES Y PROPUESTA}

La conclusión que se infiere de todo lo expuesto es que, efectivamente, no puede caber exigencia de prueba de inocencia respecto de quien ya fue declarado absuelto o sobreseído el procedimiento en el que se le investigaba como posible responsable penal (cualquiera que sea la causa). En este sentido, exigir prueba respecto de la inexistencia del hecho (ontológico) en un expediente ulterior de responsabilidad patrimonial, además de tornarse prácticamente inviable por el mismo hecho de referirse a una circunstancia negativa, vulnera indudablemente el derecho a la presunción de inocencia que, en todo proceso penal y posterior, ha de primar.

Así pues, (teniendo en consideración la redacción del artículo 294 de la LOPJ), sería deseable, de lege ferenda una generalización del derecho a una indemnización por daños a todo sujeto absuelto tras haber tenido que sufrir una prisión provisional indebida.

Aun así, consideramos que incluso de lege lata, es posible una solución interpretativa que dé respuesta al problema, de manera que la "inexistencia del hecho" jurídico-procesal (y no solamente objetivo) fuese suficiente para otorgar la indemnización al daño; es decir, cuando la sentencia hubiese sido absolutoria por falta de pruebas (cosa que, por otro lado suele ser, como se ha puesto de relieve, la tónica habitual). No obstante, mientras no se produzca este esperado cambio interpretativo en el plano jurisprudencial, siempre estará a disposición de la ciudadanía la posibilidad de acudir en amparo al Tribunal Constitucional y, en última instancia, al Tribunal Europeo de Derechos Humanos con sede en Estrasburgo.

\section{BIBLIOGRAFÍA:}

BANACLOCHE PALAO, J. La libertad personal y sus limitaciones. McGraw-Hill, Madrid, 1996.

COBREROS MENDAZONA, E. "El difícil problema de la responsabilidad patrimonial por funcionamiento anormal del Tribunal Constitucional". En Revista Vasca de Administraciones Públicas, $\mathrm{n}^{\circ} 87$ - 88, 2010.

COBREROS MENDOZA, E. "Funcionamiento anormal de la Administración de justicia e indemnización”. En Revista de Administración Pública, n 177, 2008.

DEL SAZ CORDERO, S. "La obligación del Estado de indemnizar los daños ocasionados por la privación de libertad de quien posteriormente no resulta condenado". En Revista de Administración Pública, nº 195, 2014.

DÍEZ-PICAZO, I. Poder judicial y responsabilidad, La Ley, Madrid, 1990. 
LÓPEZ SAMANES, G. "La responsabilidad patrimonial de la administración en las Leyes 39/2015 y 40/2015, de 1 de octubre" (2017). Artículo publicado en el sitio web: <https://www.notariosyregistradores.com/web/secciones/doctrina/articulosdoctrina/responsabilidad-patrimonial-administracion/>

MARTÍN REBOLLO, L. Jueces y responsabilidad del Estado, el artículo 121 de la Constitución, Centro de Estudios Constitucionales, Madrid, 1983.

OLIVA BLÁZQUEZ, F. "Responsabilidad civil de los Jueces y Magistrados por ignorancia inexcusable". En InDret. Revista para el análisis del derecho, n 4, 2010.

RODRÍGUEZ RAMOS, L. “Apariencia y realidad en la responsabilidad patrimonial del estado-juez (limitada vigencia del artículo 121 ce)". En UNED. Teoría y Realidad Constitucional, $\mathrm{n}^{\circ}$ 38, 2016.

RODRÍGUEZ RAMOS, L. "Todo preso preventivo absuelto merece indemnización (La STC 8/2017, referente de una reinterpretación del artículo 294 LOPJ)". En Diario La Ley, no 8949, 2017.

\section{Otras fuentes consultadas y jurisprudencia:}

Convenio para la Protección de los Derechos Humanos y de las Libertades Fundamentales, hecho en Roma el 4 de noviembre de 1950, y enmendado por los Protocolos adicionales números 3 y 5, de 6 de mayo de 1963 y 20 de enero de 1966.

Pacto Internacional de Derechos Civiles y Políticos, hecho en Nueva York el 19 de diciembre de 1966.

Dictamen del Consejo de Estado con número de referencia 1.207/2.015 (Justicia), emitido en la sesión de la Comisión Permanente el 4 de febrero de 2016.

STC, de 12 diciembre de 1994 (RTC 1994\325).

STC, de 26 abril de 1990 (RTC 1990176).

STS, de 7 octubre de 2003 (RJ 2003\7458).

STS, de 27 enero de 1989 (RJ 19891500).

STS, de 23 noviembre de 2010 (RJ 201018629).

STS, de 8 de mayo de 2000 (RJ 2000\4887). 